\title{
A Qualitative Exploration of Transformative Learning within an Online Leadership Course
}

Melissa M. Sweetman

Wingate University

Follow this and additional works at: https://encompass.eku.edu/jote

Part of the Occupational Therapy Commons

\section{Recommended Citation}

Sweetman, M. M. (2018). A Qualitative Exploration of Transformative Learning within an Online Leadership Course. Journal of Occupational Therapy Education, 2 (2). https://doi.org/10.26681/jote.2018.020206

This Original Research is brought to you for free and open access by Encompass. It has been accepted for inclusion in Journal of Occupational Therapy Education by an authorized editor of Encompass. For more information, please contact Linda.Sizemore@eku.edu. 


\title{
A Qualitative Exploration of Transformative Learning within an Online Leadership Course
}

\begin{abstract}
As the profession of occupational therapy enters its second century of existence, it is important to recognize that for continued sustainability and strength through the effects of healthcare reform, strong leadership is required. While experts agree that leadership development for occupational therapists needs to begin in the classroom setting, there is little existing research on occupational therapy leadership education. Built upon a theoretical framework of the transformative learning theory, this qualitative study sought to determine whether students in an online leadership course within a post-professional doctor of occupational therapy degree program believed they experienced a transformation in their leadership knowledge and skills as a result of the course. Additionally, the study sought to identify the teaching strategies and course materials that students perceived as the most beneficial to their leadership development. Summative course evaluations and written reflective forum discussions were used to examine students' personal narratives regarding the experience of the leadership course and their thoughts on which components of the course were most beneficial to their leadership development process. Findings revealed that students did indeed experience transformative learning, which provided them with a new understanding of leadership and confidence to engage in leadership opportunities. Students attributed their learning to several factors including reflection, assigned readings, peer support, and meaningful TED talk videos. Insight gained from this study's results can assist other leadership course instructors to develop a course that will facilitate a transformative learning experience.
\end{abstract}

\section{Keywords}

Leadership development, occupational therapy, transformative learning theory

\section{Creative Commons License}

(ब) (1) $(9)$

This work is licensed under a Creative Commons Attribution-Noncommercial-No Derivative Works 4.0 License.

Acknowledgements

Many thanks to Dr. Nicole Lowes for her guidance and support throughout this research study. 


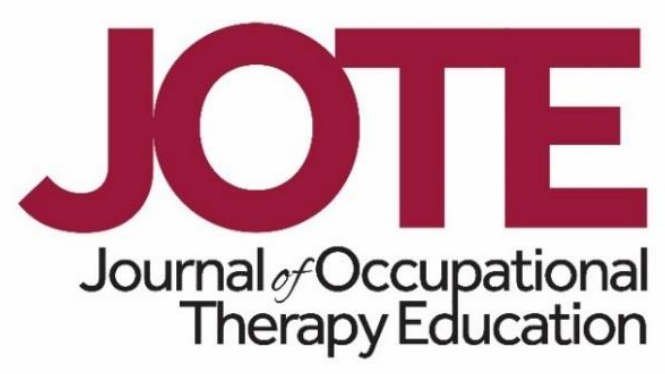

Volume 2, Issue 2

A Qualitative Exploration of Transformative Learning

Within an Online Leadership Course

\author{
Melissa Sweetman, PhD, OTD, OTR/L \\ Wingate University \\ United States
}

\begin{abstract}
As the profession of occupational therapy enters its second century of existence, it is important to recognize that for continued sustainability and strength through the effects of healthcare reform, strong leadership is required. While experts agree that leadership development for occupational therapists needs to begin in the classroom setting, there is little existing research on occupational therapy leadership education. Built upon a theoretical framework of the transformative learning theory, this qualitative study sought to determine whether students in an online leadership course within a post-professional doctor of occupational therapy degree program believed they experienced a transformation in their leadership knowledge and skills as a result of the course. Additionally, the study sought to identify the teaching strategies and course materials that students perceived as the most beneficial to their leadership development. Summative course evaluations and written reflective forum discussions were used to examine students' personal narratives regarding the experience of the leadership course and their thoughts on which components of the course were most beneficial to their leadership development process. Findings revealed that students did indeed experience transformative learning, which provided them with a new understanding of leadership and confidence to engage in leadership opportunities. Students attributed their learning to several factors including reflection, assigned readings, peer support, and meaningful TED talk videos. Insight gained from this study's results can assist other leadership course instructors to develop a course that will facilitate a transformative learning experience.
\end{abstract}




\section{INTRODUCTION}

In her Inaugural Presidential Address, American Occupational Therapy Association (AOTA) President Virginia Stoffel (2013) commented that in recent years the profession of occupational therapy had made significant strides in its level of awareness and recognition by consumers and other healthcare professionals. However, she also cautioned listeners that the work was not done yet. To continue to strengthen the profession and solidify its place in the healthcare environment, Dr. Stoffel urged all members of the occupational therapy profession to seek and embrace leadership roles. As the profession fights for its place within new healthcare regulations and reimbursement plans as part of the Patient Protection and Affordable Care Act (2013) and efforts by the current administration for repeal and/or replacement, the need for effective leadership is stronger now than ever (Stoffel, 2013).

As part of a strategic planning process for the profession, in 2007 AOTA developed a Centennial Vision statement to guide the future of the profession through its $100^{\text {th }}$ birthday in 2017. Under this vision, AOTA established four strategic directions. The first direction is "building the capacity to fulfill the profession's potential and mission" which includes "strengthening our capacity to influence and lead" (AOTA, 2007, p. 614). Since the Centennial year has now passed, AOTA aims to achieve Vision 2025, which states, "Occupational therapy maximizes health, well-being, and quality of life for all people, populations, and communities through effective solutions that facilitate participation in everyday living" (AOTA, 2017, p.1). Vision 2025 builds upon the Centennial Vision and includes four anchoring guideposts of accessibility, collaboration, effectiveness, and leadership (AOTA, 2017). Furthermore, the AOTA Strategic Goals and Objectives: 2014 to 2017 (AOTA, 2013) echoes these visions with the first goal being, "building the profession's capacity to fulfill its potential and mission" with an objective to "strengthen our capacity to influence and lead" (para. 1). As such, it is important for occupational therapy curricula to contribute to the development of strong leaders who will act as practice scholars. This study explored student perceptions of a post-professional leadership course with particular focus on transformative learning and pedagogical design.

\section{BACKGROUND}

To prepare occupational therapists for leadership that will strengthen and sustain the profession, there must be an increased focus on leadership development. The term "leadership" defines the actions that one takes as a leader. Leadership is a complex social exchange that relies upon interaction between the leader and the followers (Dinh et al., 2014). It is a process through which change or action takes place with the aim of fulfilling a shared purpose (Dinh et al., 2014). Fleming-Castaldy and Patro (2012) studied the leadership skills of occupational therapists in practice and found that those who served in management positions did indeed identify themselves as leaders, in accordance with the exemplary practices of leaders identified by Kouzes and Posner (2012). These exemplary practices include modeling the way, inspiring a shared vision, challenging the process, enabling others to act, and encouraging the heart (Kouzes \& Posner, 2012). However, this study did not identify how or why these therapists developed those leadership skills. A study by Scott (1985) also examined leadership 
skills of practicing clinicians. Scott's study focused solely on female occupational therapists, and sought to identify what factors contributed to the development of leader characteristics within this population. The questionnaire used to collect data centered upon social history, work history, gender and sex roles, and roles within marriage and family. Findings demonstrated the importance of familial, spousal, and professional support/encouragement as well as early identification of those with potential and interest in becoming leaders so that ongoing leadership training can be provided. It is important to note that this study took place during an era in which the social expectations for women were much different than they are today.

Developing leadership skills can be done through a variety of methods. Many occupational therapy educational programs at both the entry-level and post-professional level include the topic of leadership within the curriculum, but there is not a consistent format, outline of content, or pedagogical design. Furthermore, while there have been a few studies conducted on leadership development within the higher educational arena (Dopson et al., 2016) and a study on transformative learning in a post-professional doctor of occupational therapy program (Provident et al., 2015), none have been conducted on the process and outcomes of a leadership course within a postprofessional occupational therapy degree program specifically related to leader and leadership development. In fact, research on the topic of leader and leadership development for occupational therapists is particularly scant despite the strong push for leadership within official documents of the AOTA.

While there is a significant lack of research regarding leadership development for occupational therapists, there is research on the topic of leadership education and pedagogy in higher education. Studies consistently support a leadership course design that is experiential, collaborative, application-based, and requires active engagement (Bayer, 2012; Kiersch \& Peters, 2017; Singleton, 2012; Smith, 2005). According to Jenkins (2012), the use of class discussion is the most widely used technique within leadership courses. Furthermore, Harvey and Jenkins (2014) assert that the use of guided reflection serves as a mechanism for developing a deeper level of learning through reflecting on and analyzing previous knowledge or experiences.

Reflection can be a key component of the learning process. The concept of transformative learning, based on the transformative learning theory by Mezirow (1997), follows the principle that adult learners experience a transformation in the way they view experiences and formulate perspectives through critical reflection. With pedagogical techniques designed to foster critical reflection, students are able to examine their current beliefs, challenge their assumptions, and formulate new knowledge and patterns of thinking (Lévesque, Hovey, \& Bedos, 2013). The way in which a professor sets up a classroom and designs a course can either facilitate or inhibit transformative learning (Haber-Curran \& Tillapaugh, 2015). Student-centered approaches that foster personal reflection in a socially supportive environment are reported to be highly influential in transformative learning experiences (Fletcher, Zuber-Skerritt, Bartlett, Albertyn, \& Kearney, 2010; Haber-Curran \& Tillapaugh, 2015; Lévesque et al., 2013; Provident et al., 2015). While there is considerable research on general education and pedagogical 
strategies related to leadership education, none specifically tailors to education for occupational therapists within a leadership course.

The primary purpose of this study was to explore the lived experiences of students who matriculated through an online academic leadership course through the lens of transformative learning theory. In doing so, insight was gained into pedagogical strategies that can be used to design other academic leadership courses. Specific research questions $(R Q)$ that were used to guide this study are as follows:

RQ 1. What are the lived experiences of students regarding transformative learning of leadership knowledge and skills within an online doctoral level leadership course?

RQ 2. How do students describe their leadership learning experiences in relation to their ability to expand on current viewpoints, create new viewpoints, change viewpoints, and/or by increased awareness and reflectivity of their personal biases and assumptions?

RQ 3. How do students describe their approach to leadership upon completion of the course; do they report an increase in knowledge and/or use of a particular leadership theory?

RQ 4. What teaching strategies and course materials did students perceive as being most beneficial to their leadership development?

\section{METHODOLOGY}

This study utilized a qualitative phenomenological approach. Qualitative research is grounded in the constructivist philosophy. Constructivism holds that there is no single truth or reality, but that knowledge and meaning of a phenomenon are constructed based upon one's experiences, interactions with others, and context (Creswell, 2014; Merriam, 2009; Rudestam \& Newton, 2015). A phenomenological approach is best utilized to gain a deeper understanding of a participant's perspective on a particular experience and how that experience has been internalized (Merriam, 2009). As such, phenomenological studies illuminate the essence of the experience or the phenomenon through the lens of the participant's perspective (Sloan \& Bowe, 2014).

Institutional Review Board approval was granted for this study. No informed consent was required and there was no risk to participants because data collected were existing data that were part of the students' typical experience within the course under study. Permission to access student assignments and end of course evaluations was received from the university at which the online leadership course was taught. Although the students from whom the data were collected were no longer affiliated with the university at the time of the study, the data were still de-identified.

This study relied upon retrospective review of two data sources- summative course evaluations and written reflective forum discussions, to collect participants' personal narratives regarding the experience of a leadership course and their thoughts on which components of the course were most beneficial to their leadership development process. Data sources were selected purposively and conveniently and were derived 
from post-professional occupational therapy doctorate (OTD) students enrolled in an online, two-credit hour leadership course that was taught in a university located in the western United States. The use of document review rather than personal interviews (which are typical for phenomenological research) was chosen for this study as personal documents can offer insight from the participant's perspective without altering the setting or experience (Merriam, 2009).

Students enrolled in the OTD program must have had a minimum of one year of clinical experience as an occupational therapist, held an entry-level degree from an accredited occupational therapy degree program, and held an active license to practice occupational therapy in the United States. Methods of data collection included answers to open ended questions on anonymous summative course evaluations and written reflective forum discussions completed by students during the final unit of the course. Data from five cohorts of students $(n=162)$ who matriculated through the course between 2014 and 2016 were analyzed.

The course under study was divided into seven distinct units, each with assigned readings, videos, audio lectures, required website engagement, and other instructional materials. There were two assignments in the form of reflective papers, and five forum discussions, each containing a reflective component that aligned with the transformative learning theory. While there were a minimum number of required posts for each student within the forum assignments, the majority of students engaged in rich discussions that moved beyond the required number of posts. The final forum discussion was used for the purposes of this study. The objective of the unit was for students to reflect on what they learned in the course, in other courses within the doctoral program, and on their past leadership experiences as they formulated plans for future leadership endeavors. Students were provided with a prompt from the instructor that served as a guide for reflecting upon how the person-environment-occupation (PEO) model applied to the student and his/her occupation of leading. They were also prompted to reflect upon their perceptions of themselves as leaders and how they envisioned their futures as leaders. The overwhelming majority of data for this study was derived from the forum posts (500 comments from 162 students).

Summative course evaluations were used to examine students' thoughts on which components of the course were most beneficial to their leadership development process. Comments regarding how the course could be improved were also analyzed. End of course summative evaluations were distributed to students electronically two weeks prior to the end of the semester and were open for completion through two weeks following the end of the semester. For the purposes of this study, responses to open-ended questions were utilized. Only a small portion of the data from this study was derived from the course evaluations (111 comments from 113 students). Questions from the course evaluations that were used for the purposes of this study are:

1. Please comment on what portions of this course were most effective to your learning.

2. Please comment on the course director's strengths and educational methods.

3. Please comment on how the course could be improved. 


\section{Role of the Researcher}

In qualitative research, the researcher often assumes the role of research instrument, meaning that he or she uses information gathered independently and directly rather than relying upon an instrument that was developed by another researcher (Creswell, 2014). Furthermore, qualitative data analysis often requires that judgments be made that could potentially be influenced by the researcher's personal experience, opinions, worldview, and relationship with the study context and/or participants (Leedy \& Ormrod, 2016). As such, it is important for the researcher to clearly state any biases, assumptions, or views that may impact the way she viewed the data. The researcher of this study served in a primary role as Program Director and Assistant Professor within the post-professional OTD program in which the leadership course under study was taught. The researcher also designed and taught the leadership course in which the primary data were generated through a course assignment. The researcher was a graduate of the program under study, and while she did not take the specific course under review, she may have had a biased perspective on the leadership transformation of students who graduate from the program experience.

\section{THEORETICAL FRAMEWORKS}

A theoretical framework provides structure to a study and offers a lens through which the researcher views the data. It is the combination of underlying assumptions, beliefs, and opinions that form a foundation upon which the study evolves (Merriam, 2009). Such a framework aids in the development of research questions and facilitates the organization of data for analysis (Creswell, 2014). Two theoretical frameworks formed the scaffold for the current study: transformative learning theory (Mezirow, 1997) and the PEO model (Law et al., 1996).

The transformative learning theory is well suited for studying leadership development in an academic environment. Mezirow's (1997) theory of transformative learning is based on the principle that adult learners experience a transformation in the way they view experiences and formulate perspectives through "critical reflection on the assumptions upon which [one's] interpretations, beliefs, and habits of mind or points of view are based" (p. 7). Learning occurs through four distinct processes: expanding on current viewpoints, creating new viewpoints, changing viewpoints, and by increasing awareness and reflectivity of one's personal biases and assumptions (Mezirow, 1997). Another key principle of the transformative learning theory is that adult learners utilize educational experiences to facilitate autonomous thinking. This type of thinking is different from recalling facts and skills from rote memory. Rather, it is a higher level cognitive skill that allows one to critically and reflectively examine his or her knowledge, skills, and beliefs and validate his morals and values through dialogue with others who may share the same beliefs (Mezirow, 1997). Within this study, the transformative learning theory guided the analysis of student perceptions of their experiences with the leadership course. In so doing, pedagogical factors of transformative learning were identified for use in future leadership course design. 
The PEO model was developed in the mid-1990s by a team of occupational therapists who recognized the importance of the environment on the occupational performance of individuals. Law et al. (1996) theorized that the person, environment, and occupations of choice were not isolated from each other, but were in fact interdependent in a transactive fashion. People, environments, and occupations are not static; rather, they are ever changing based on other contextual factors. The interplay between these dynamic constructs determines occupational performance success. According to the model, environmental characteristics overlap with the person's skills and the demands of the occupation resulting in occupational performance (Law et al., 1996). The online leadership course under study was developed around the PEO model, facilitating students' ability to examine their environments, skills, and demands in relation to not only their leadership occupations, but also in relation to their leadership development process.

\section{DATA ANALYSIS}

Carpenter and Suto (2008) described the process of qualitative data analysis as taking place in three phases: data reduction, data display, and conclusion drawing/verification. In the first phase, data reduction, the researcher reviews the raw data and makes decisions about which data to keep. In other words, she must decide which data will help answer the research question and which data are extraneous. Reducing the data to only the relevant data will facilitate the process of data display. For the purposes of this study, raw data were reviewed line by line and purely congratulatory comments as well as comments about employment were removed from forum discussions. Additionally, quantitative data collected as part of the summative course evaluations were also discarded.

The second phase of data analysis involved physically displaying the data in an organized fashion to delineate codes and categories. Doing so can highlight commonalities that lead to the identification of common themes within the data. NVivo11 software (QSR International, 2015) was utilized to organize and display the data. Nodes were created to reflect the four research questions. A node essentially functioned as a file folder in which data correlating to the topic of the node are stored. Categorizing the data allowed for themes to emerge throughout the coding process thus leading to the development of sub-nodes.

Once the data were displayed, the third phase of data analysis began. It was during this phase that the researcher began formulating conclusions about the emergent themes. At the root of qualitative data analysis lies an inductive process to determine codes, categories, and themes that lead to an understanding of the students' perceptions related to their leadership development experience and to the pedagogical strategies used within the course. Inductive analysis involves a bottom up approach beginning with specific observations then drawing general conclusions. Initially, open coding was used to begin identifying sub-nodes that were then categorized within each node through the 
process of axial coding as data from each cohort's forum responses and from each cohort's course evaluation comments were analyzed for commonalities. These commonalities were identified as themes through the process of selective coding (see Table 1).

Table 1

Organization of Data

\begin{tabular}{|c|c|c|c|c|}
\hline Nodes & $\begin{array}{l}\text { Leadership } \\
\text { Views }\end{array}$ & $\begin{array}{l}\text { Learning } \\
\text { Experiences }\end{array}$ & $\begin{array}{l}\text { Learning } \\
\text { Methods }\end{array}$ & $\begin{array}{l}\text { Transformative } \\
\text { Learning }\end{array}$ \\
\hline Subnodes & $\begin{array}{l}\text { Newfound } \\
\text { Confidence as } \\
\text { a Leader } \\
\text { Continuous } \\
\text { Learning is } \\
\text { Necessary }\end{array}$ & $\begin{array}{l}\text { There is a } \\
\text { Difference } \\
\text { Between a } \\
\text { Leader and a } \\
\text { Manager }\end{array}$ & $\begin{array}{l}\text { Peer Support } \\
\text { Readings } \\
\text { Reflection } \\
\text { TED Talks }\end{array}$ & $\begin{array}{l}\text { Expanded } \\
\text { Definitions of } \\
\text { Leadership } \\
\text { Leadership } \\
\text { Development } \\
\text { is a Journey } \\
\text { Person- } \\
\text { Environment- } \\
\text { Occupation } \\
\text { Model }\end{array}$ \\
\hline
\end{tabular}

\section{RESULTS}

Seven themes emerged from the data analysis process: (a) leadership development is a journey; (b) the PEO model guides leadership development; (c) expanded definitions of leadership; (d) there is a difference between leadership and management; (e) newfound confidence in leadership abilities; ( $f$ ) ongoing learning is necessary; and (g) a variety of teaching strategies significantly contributed to learning. Each of these themes was then categorized according to the research questions. Within the four categories there were themes that were significantly more prevalent than others, such as leadership development is a journey (see Table 2). 
Table 2

Thematic Organization

\begin{tabular}{|c|c|c|}
\hline Research Question & Themes & $\begin{array}{c}\text { Number of } \\
\text { references coded }\end{array}$ \\
\hline $\begin{array}{l}\text { What are the lived experiences of } \\
\text { students regarding transformative } \\
\text { learning of leadership knowledge and } \\
\text { skills within an online doctoral level } \\
\text { leadership course? }\end{array}$ & $\begin{array}{l}\text { Leadership } \\
\text { development is a } \\
\text { journey } \\
\text { Person- } \\
\text { environment- } \\
\text { occupation as a } \\
\text { guide }\end{array}$ & $\begin{array}{l}118 \\
12\end{array}$ \\
\hline $\begin{array}{l}\text { How do students describe their } \\
\text { leadership learning experiences in } \\
\text { relation to their ability to expand on } \\
\text { current viewpoints, create new } \\
\text { viewpoints, change viewpoints, and/or } \\
\text { by increased awareness and reflectivity } \\
\text { of their personal biases and } \\
\text { assumptions? }\end{array}$ & $\begin{array}{l}\text { Expanded } \\
\text { definitions of } \\
\text { leadership } \\
\text { There is a } \\
\text { difference } \\
\text { between leader } \\
\text { and manager }\end{array}$ & 72 \\
\hline $\begin{array}{l}\text { How do students describe their } \\
\text { approach to leadership upon completion } \\
\text { of the course; do they report an } \\
\text { increase in knowledge and/or use of a } \\
\text { particular leadership theory? }\end{array}$ & $\begin{array}{l}\text { Newfound } \\
\text { confidence in } \\
\text { leadership abilities } \\
\text { Ongoing learning } \\
\text { is necessary } \\
\text { Leadership styles }\end{array}$ & $\begin{array}{l}35 \\
25\end{array}$ \\
\hline $\begin{array}{l}\text { What teaching strategies and course } \\
\text { materials did students perceive as } \\
\text { being most beneficial to their leadership } \\
\text { development? }\end{array}$ & $\begin{array}{l}\text { Reflection } \\
\text { Readings } \\
\text { Support and } \\
\text { encouragement } \\
\text { from peers } \\
\text { TED Talks }\end{array}$ & $\begin{array}{l}57 \\
53 \\
32\end{array}$ \\
\hline
\end{tabular}




\section{Leadership Development Is a Journey}

The most predominant theme within this study was that leadership development is a journey. In fact, students within the forum mentioned the word journey 187 times. While comments in which students simply congratulated each other on completing the journey were excluded from analysis, many students thanked each other for being on the leadership development journey together, indicating the importance of a shared experience. For example, some of the specific students' comments were: "It has been a pleasure to go through this journey with you" (Student 3); "It has been an honor to have experienced this journey with you" (Student 35); "I am thankful to have shared this journey with you" (Student 42); "This journey has been a true gift" (Student 80); and "I thank each of you for such an amazing journey" (Student 146).

Students also commented on their emotions related to their journey. For example:

"I write this with mixed feelings as I am happy to have completed this seemingly endless journey, yet a bit lost as I have come to enjoy the posts as a thread that connected, shaped, and framed all aspects of this program" (Student 12). Other comments included: "I am excited for the next phase of our journey" (Student 55); "I would often confuse goals to achieve with the final destination, and then when I achieved them I was saddened that the journey was over" (Student 122); and "As we approach completion of this journey, I am excited by the roads that lay ahead and the journey into the future" (Student 158).

Additionally, students commented on the benefits they believed to have gained from the process of the journey. For example: "My view of leadership has morphed and evolved because of the OTD journey in such a positive career-changing manner" (Student 14); and "I feel well prepared to continue along the journey as I explore the opportunities that will assist me in promoting our profession in a leadership role" (Student 116). Another student expressed similar sentiments that included an expansion of his/her ability to influence others and the profession: "Therefore, as a result of this journey, my goals and dreams have expanded to include the Centennial Vision and to spotlight our profession in this new medical paradigm, as we become leaders in this new frontier that promotes health and wellness" (Student 146).

\section{Person-Environment-Occupation (PEO) Model as a Guide}

The PEO model is utilized within occupational therapy practice as a framework by which a client intervention is organized. Occupation-based models such as the PEO guide the clinician through the continual assessment of the interactions between the client, his desired occupations, and his context (Cole \& Tufano, 2008). Within the online leadership course, students were asked to view their occupation of leading through the PEO model. One student analyzed his/her leadership growth as a combination of personal skills (person), environment, and leadership (occupation), stating:

Using the PEO model, I have really come to understand how many factors play into being an efficient leader. First, I must have the appropriate skills to be a leader. Some skills will come effortlessly, others I will have to chisel at until they are just as I need them to be. Second, I have been given an environment that will 
foster my being a leader. I work with an amazing group of women that have supported and fostered this [educational] experience....And lastly, I have to accept leadership as an occupation. This is probably the most difficult for me as I am typically a behind the scenes person that doesn't want any attention brought upon me, but I am learning to step a little towards the front (Student 4).

Likewise, another student stated:

Reflection has taught me that although the PEO model could be applied to my leadership roles in the past, there were many flaws. I (the person) was not functioning as the dynamic component that I should have been...Being rigid resulted in difficulty adapting to the frequent environmental changes within the work setting...Taking the time to correlate my leadership roles with the PEO model has allowed for a renewed perspective and outlook on my professional future. I now see myself as a leader who has the potential to influence change.

Accepting the role of leader as an occupation means that I will no longer view the components of the PEO model as separate entities that battle against one another resulting in imbalance and frustration. Instead, I will strive to understand that the components of the PEO model are ever connected and therefore dynamically interact to achieve a sense of harmony (Student 6).

Some students were familiar with the use of the PEO within clinical practice, but had not thought to apply it to themselves as leaders. For example: "I had never really considered how the PEO model could be applied to myself and the occupation of leading; however, the PEO is a very fitting model, not only for the [occupational therapy] services I provide on a daily basis, but also in terms of becoming a leader in my current practice setting. I must consider the occupational goals and outcomes for me as a leader and put into action a plan that will help me achieve these occupational goals. In doing so, the PEO model can be used to ensure that the environment in my work setting is a good fit for me and my needs to become an evidence-based leader" (Student 8).

Other students expressed positive feelings in relation to the newly discovered personal use of the PEO model. For example: "One of my favorite shifts has been viewing leadership through the lens of occupation. No longer do I see leadership as an ambiguous characteristic I hope to catch, but rather, now I view leadership as an occupation to be developed by examining my own personality, combined with setting up my environment to create opportunities, and purposefully practicing skills that result in increased occupational performance related to leadership. Viewing leadership as an occupation has been freeing and inspiring to me- it operationalizes the process that I can utilize to develop leadership skills for myself, but also gives me a framework for mentoring others" (Student 109).

\section{Expanded Definitions of Leadership}

The most prevalent theme in relation to the students' experiences with changing viewpoints was the expression of new definitions of leadership. Some students shared their perspectives of personal growth and evolution. For example: "My views on 
leadership grew from the progression of theories/philosophies and how to apply personal leadership skills in everyday settings and in our profession" (Student 3); "As a result of this journey, my view of leadership has changed and evolved" (Student 11); and "I must admit, I did not think of leadership as an occupation prior to this course. The entire course provided so many lessons to guide us in future leadership ventures" (Student 13).

Some students expressed the fact that their viewpoints on their own ability to function as a leader had changed. For example: "When I first began this program...I thought leadership was about changing the world, about directing followers on a great adventure into new theories, frameworks, and interventions... Now that I have gone through this course, I have taken away a whole new perspective of leadership. I am a leader every day, not only to the staff members around me, but to my clientele as well. This eyeopening experience has empowered me to become an even better leader by expanding into new contexts, and interacting with different patient populations" (Student 2); and "I see my definition of leadership expanding toward everyday influences and less focused on single accomplishments or events. I see a leader more as a planter of seeds and a gardener/agent for positive change than the All-Star player with the highest home run average in the game" (Student 109).

Several students expressed learning the distinction between a titled leader and an emergent leader and the fact that one does not require a formal titled position to serve as a leader. The following quotes represent this experience: "Throughout taking this leadership course, I have learned that leadership is not a title, and can take many forms. Whether it is leading my patients and families as I provide them with services, educating my peers, advocating for the profession, or engaging in new emerging practice areas, I am being a leader" (Student 15); "Prior to this course, I thought you could only be a leader if you were [in a management position] and I would always tell that little voice in my head it was not my place to make changes. Now, I cannot wait to see how else I can lead change" (Student 156); and "I am now recognizing that I don't need to perform huge acts to be a leader in my profession. I tend to prefer to work behind the scenes, and those small acts can influence change and lead fellow coworkers. The occupation of leadership to me now means asking myself on a daily basis what I can do that day to make a difference" (Student 134).

\section{There Is a Difference between Leader and Manager}

The fact that there is a distinction between leadership and management seemed to be a novel idea for many students. Frequently, students highlighted the transformational discovery of this concept. For example: "Before starting this course, I thought a manager and leader were the same. Well, I now know I thought wrong. I currently hold a management position; however, I want to be known as a leader. I want to be a change agent" (Student 1); "I was relieved to learn that leadership was not synonymous with management, as I still have no desire to be a part of upper management" (Student 2); and "I used to think that management was the same as leadership in the past, and this course showed me a new definition of leadership in occupational therapy within the community" (Student 10). 
Likewise, Student 59 and Student 128 expressed learning similar concepts related to management and leadership: "Prior to pursuing a doctoral degree, my understanding of leadership was limited at best even though I held a managerial position overseeing the occupational therapy department at our facility. The distinction between manager and leader was not evident to me as I assumed they were similar roles" (Student 59); and "Prior to taking this class I did not consider myself a leader...Since completing this course, I have learned the difference between management and leadership.

Management is about controlling a group to accomplish a goal. Leadership consists of one's ability to influence, motivate, and enable others to achieve success. I now know that influence and inspiration separate leaders from managers" (Student 128).

\section{Newfound Confidence in Leadership Abilities}

Students reported a sense of new confidence in their leadership abilities. For example: "I am now empowered and understand that I can be a leader of change" (Student 2); "I am better equipped to be a true leader rather than a manager and am almost excited about taking on leadership roles" (Student 4); "I feel well equipped and much more capable now leading multidisciplinary teams, further developing therapeutic programs, and revamping our documentation" (Student 11); and "I never dreamed this course would provide me with the knowledge for being a scholar plus provide me with the confidence and courage to lead and grow my organization" (Student 13).

Other students reported: "I feel confident in my ability to meet the demands of leading the change I seek to create" (Student 121); "I can now take my newly acquired and developed skills and knowledge, and feel more confident when I accept or seek out leadership opportunities" (Student 127); "Reflecting on this semester, I can summarize the biggest change in my perception of leadership that has occurred during this course in five words- I am not afraid anymore" (Student 158); "As a result of taking this course, I feel empowered to take on leadership roles" (Student 67); and "I feel empowered to go forth and be a leader in the OT profession. I believe the material learned in this course pushed me to grow the most" (Student 71).

\section{Ongoing Learning is Necessary}

Many students expressed their belief that the learning process is just beginning; leaders must always continue to seek ways of further developing and maintaining their leadership skills. Furthermore, many students reported that they looked forward to continuing leader/leadership development. For example: "I am eager to continue learning and growing as a leader so that it hopefully becomes natural for me to step into leadership positions and to perform in that position well" (Student 4); "Although I feel I have made progress toward becoming the leader that I would like to be, I also have come to appreciate the fact that my leadership development is a work in progress" (Student 6); "I realize that my leadership development process is only beginning- a project in development" (Student 7); and "I also realize that I must continue learning in order to be an effective leader" (Student 13). 
Similarly, Student 12 and Student 59 articulated their thoughts on a continued process of leadership development: "The concept of leadership that we know today will evolve tomorrow because there will be forces upon it that will make us change or adapt to it, thus grow...While eye opening, humbling, and sometimes heartbreaking, this educational and reflective process has led us to learn the skills we thought we'd never have, and revealed aspects of ourselves that we can joyfully build upon starting today, and tomorrow, and the day after that" (Student 12); and "I also think that a person must learn necessary skills in order to lead effectively if they expect people to follow them. I also believe that having the ability to influence others is a process that takes time to develop that requires recognition of one's strengths and weaknesses" (Student 59).

\section{Leadership Theories}

Students specifically mentioned authentic, servant, and transformational leadership theories in their comments. Most comments related to the students' ability to recognize themselves as a particular type of leader or to their aspirations of becoming either an authentic, servant, or transformational leader.

Authentic leadership was the most widely mentioned leadership theory. Student comments included: "It takes an authentic leader to recognize and address toxic stress in infants' and toddlers' lives while still being receptive to and guiding/coaching parents" (Student 38); and "I look forward to implementing more of an authentic leadership style, fostering trust within my team while building confidence among team members through increasing the credibility of myself as the leader, and leaving behind an admirable legacy of leadership" (Student 161).

Servant leadership was the next most commonly cited leadership theory. Students reported: "While my natural gift was for people, I could only manage as a behind-thescenes servant leader. It is my hope that I can continue to help others create positive change in their lives" (Student 38); "I identify most closely with the leadership style of a servant leader. People are the most important part of leadership and gaining their trust is important to me" (Student 48); "Before this class, I knew what servant leadership was, but really had not considered it in contexts outside of faith-based or service environments" (Student 50); and "Even though I have held leadership positions, I do not consider myself a leader. I tend to view myself more as a servant to the people. A servant leader is characterized as prioritizing other people's needs before their own. My goal for obtaining this doctorate is to be able to offer a voice for some of the people that might not have a voice" (Student 153).

Transformational leadership was the least frequently mentioned theory. However, a few students did discuss transformational leadership. For instance: "Whether it is the role of servant leadership, situational leadership, or transformational leadership, I can now see how every individual has the ability to assume the role of a leader in their own environment" (Student 37); "Some of the qualities I recognized in myself pertain to servant, transformational, and collective leadership styles" (Student 165); "Now instead of assuming and carrying out responsibilities following the premise of a situational leadership model, I have started to utilize a transformational leadership model for 
guidance" (Student 166); and "The readings from this course inspired me to become a transformational leader. I want to perform 'idealized influence' by setting a good example to my own kids and my students. I also want to motivate and inspire these children to do their best in everything they do. I want to employ 'intellectual stimulation'. I want these children to make the right choices not only because they feel the need to follow my authority, but also because they know the reasons behind their actions. I also want to employ 'individualized consideration'. I want to tap into their skills and help them maximize their potential" (Student 88).

\section{Reflection}

The skill of reflection is one that many students reported as being key to the leadership development process over the course of the semester. For example, within the final course forum, students reported: "I never truly appreciated the value in deep reflection. I think we all know ourselves better now. We are comfortable looking within our souls and making decisions based on these meaningful reflections" (Student 14); "I can reflect back on life experiences and feel humbled and empowered, by recognizing I have held positions of leadership. Throughout this process, I feel I have gained a better understanding of myself, which is one of the primary occupations of a leader" (Student 37); and "I have been able to reflect upon areas in my current position that I may be able to further develop and assume more of a leadership role" (Student 40).

Similarly, students stated: "This is the beauty of reflection. It allows one to dig deep inside to determine the best decisions for the future. This course has taught me the value of the following lessons or skills associated with effective leadership: reflection, introspection, mentoring, leadership assessment tools, and most importantly how to be a leader for change" (Student 13); and "As a life-long learner, self-reflection will improve my individual leadership skills that are instrumental in helping guide and influence others. Prior to this program, I was not actively participating in self-reflection activities that I now see are important pieces to optimizing my leadership skills" (Student 60).

Course evaluations completed by the students also highlighted reflection as one of the strategies that was most beneficial to their learning. In response to the prompt on the course evaluation, "Please comment on what portions of this course were most effective to your learning," anonymous student comments included: "Reflection papers and forum interaction with peers;" "Reflection was a key component to my personal growth;" "The reflective aspect of the leadership course was the most effective aspect for me;" "I enjoyed the reflective aspects of this course and the ability to think deeper into who I am and what I strive to achieve in my leadership abilities;" and "I felt like I got to know myself better through the self-reflection required of the forum posts and papers this class required."

\section{Readings}

Student forum posts included many comments indicating that the readings were enjoyable and instrumental to their learning process. For example: "Through the readings and reflecting on my academic and professional growth since enrolling in this program, I have come to realize that I was not, in its true definition, a leader" (Student 
6); "Through the past semester reading various leadership books and articles, I learned so much about myself and how I view who I am as a leader" (Student 54); "The readings from this course inspired me to become a transformational leader" (Student 88); and "Throughout this course, my perceptions of myself as a leader and of leadership have been challenged by the readings and by the questions and reflections posed in the forums" (Student 123).

Anonymous course evaluation comments also referenced the readings as being most effective for their learning process. For example: "Excellent choice of textbooks;" "The textbooks were enlightening and offered wonderful guidance;" "It was one of the those classes where the books were completely relevant and I read all of the readings;" "I enjoyed the type of research articles used to facilitate learning for this course;" and "[The professor] provided a variety of articles and practical examples to encourage a breadth of opportunities to learn about leadership styles. It seemed very effective to me as a student who was unaware of the depth of this topic."

\section{Support and Encouragement from Peers}

Students frequently cited support and encouragement from their peers as beneficial to their learning. While this is not a specific pedagogical strategy on its own, the large class sizes and intentional design and facilitation of the forums by the professor certainly contributed to the engagement of classmates with each other. Student comments relating to peer support were primarily formed as thank-you notes to their classmates. For example: "I have learned a lot from you in a short period of time. I am eternally grateful” (Student 6); "One significant 'a-ha' moment for me was the realization of how much leaders support and rely on the growth and expertise of those surrounding them" (Student 9); "I especially enjoyed learning about the styles and perspectives of my fellow cohorts, whom I've learned so much from" (Student 12); and "I now realize that mentoring is a worthwhile occupation in itself and has great potential for building capacity within our profession" (Student 57).

\section{TED Talks}

Videotaped TED Talks were assigned throughout the course as required preparatory materials. Students frequently cited TED Talks, especially one conducted by Drew Dudley (2010). Comments included: "As Dudley noted in his TED Talk, we are all leaders in our own way, and our leadership takes on different forms, and occurs in different contexts for different people" (Student 12); "I enjoyed the 'lollipop' story as told by Drew Dudley in his TED Talk. I always felt that if I could influence one person in one small way, I was a good leader" (Student 48); "Drew Dudley's explanation of everyday leadership resonates with me. I see my definition of leadership expanding toward everyday influences and less focused on single accomplishments or events" (Student 109); and "Moreover, I have been inspired by the words of Drew Dudley to re-envision my leadership abilities in ways that allow me to be more comfortable and enthusiastic about my career and myself" (Student 118). 
Other students concurred, stating: “Dudley's 'lollipop moments' are something that everyone can do to create differences in others' lives. This definition has enlarged the picture of how I understand leadership and how I can effect change in others" (Student 131); and "Leadership as described by Drew Dudley in his TED Talk comes from 'lollipop moments' in which we take the time to understand the needs of our peers and our patients. In that respect, I can call myself a leader" (Student 133).

\section{DISCUSSION}

Generally, the lived experience of the students within the leadership course can be described as centering on reflection and empowerment. Students discovered that leader and leadership development is an ongoing journey that must become a lifelong process for optimal leadership success. Students also realized that by redefining leadership as an occupation, they were able to utilize occupational therapy models of practice such as the PEO model to analyze occupational performance and determine what needed to be learned or improved to maximize leadership potential. Just as occupational therapists analyze the client factors, performance skills, and context to determine the best way of enabling performance of a client's desired occupation, students realized that when leadership was viewed as an occupation, so too can the determinants of successful performance be identified.

The discovery of the distinction between leadership and management as well as the distinction between emergent and titled leadership led students to recognize true leadership and fostered a sense of excitement to develop their leadership skills and explore leadership opportunities. Through the transformative experience of redefining leadership, students developed a newfound sense of confidence, not only in their current roles, but also in the possibility of future leadership roles. Emotions such as excitement and confidence are frequently associated with change. Fitzpatrick and Stalikas (2008) asserted that when individuals experience positive emotions, they are more open to new possibilities thus leading to the ability to "contemplate new ideas, develop alternative solutions to problems, reinterpret their situations, reflect on behaviors, and initiate new courses of action and creative endeavors" (p. 139).

Finally, students attributed the transformative experience to course readings, meaningful TED Talks, peer support, and reflection. The use of carefully selected course readings and supplemental videos such as TED Talks provided diversity in the types of learning materials that was beneficial to improving student engagement and learning (Bangert, 2004; Taylor, 2007). A prevalent theme among student comments was appreciation of support from classmates. While mentorship was not intentionally designed as an instructional strategy for the leadership course, it became apparent that mentoring relationships developed between students. Research has suggested that supportiveness is a key factor in mentoring relationships leading to a sense of empowerment on behalf of the mentee (Terrion \& Leonard, 2007). Reflection is a key component of transformative learning and is best utilized through a guided approach that leads students through the process of simple reflection building to critical reflection 
that enables students to reevaluate previously held beliefs and assumptions (Mezirow, 1997; Ryan, 2013). Reflection allows one to change old patterns of thought and develop new depths of knowledge (Lévesque et al., 2013).

Transformative learning experiences allow students to assimilate new material through introspection and critical reflection such that they may expand current viewpoints, create new viewpoints, or change viewpoints (Mezirow, 1997). Themes discovered through data analysis correlated with each of these constructs. For example, students expanded current points of view by recognizing that leadership development was a journey and by expanding their definitions of leadership. New viewpoints were created as students learned that an occupation-based model such as the PEO could be used to frame their occupations as leaders and guide their continued development. Student viewpoints were changed as they learned the difference between a leader and a manager and discovered a newfound confidence in their abilities and potential as leaders. Lastly, students deepened their sense of reflectivity as they practiced scaffolded reflection skills and recognized how reflecting on their skills led to the knowledge that ongoing learning is necessary to continued growth as leaders. These new and expanded viewpoints were evidence of the students' abilities to think autonomously following critical reflection and collaborative dialog with their peers (Taylor, 2007).

Results of this study showed that indeed students did indicate that a transformative learning experience took place. Because of this transformation, these students felt prepared and empowered to take on the leadership roles necessary to continue strengthening the profession and effect the change that is needed to propel the profession of occupational therapy through its second century of existence. As such, occupational therapy educators can learn from the pedagogical design and instructional elements contained within this course to facilitate future transformational learning experiences.

\section{IMPLICATIONS AND RECOMMENDATIONS}

Due to limitations and demands placed upon the profession by the ever changing healthcare environment, strong leadership is needed now more than ever. Building the capacity for leadership will enable the profession to continue to adapt and thrive well into the future. Occupational therapy educators can play an important role in building such capacity. Research shows that leadership education for occupational therapy practitioners must begin in the classroom (Farkas, 2014; Heard, 2014); however, there is very little existing research on the topic of occupational therapy leadership education. This study has important implications that will help fill the gap in occupational therapy leadership evidence.

\section{Theoretical Implications}

Although the purpose of this study was not to develop new theory, findings do support the existing transformative learning theory. According to Mezirow (1997), human beings create habits of mind and points of view that comprise a frame of reference regarding a particular concept. Learning takes place through the evolution of those frames of reference. In order for learning to occur, critical reflection upon one's core beliefs and 
assumptions must take place. Learning involves expanding current points of view, establishing new points of view, transforming points of view, and deepening one's sense of reflectivity (Mezirow, 1997).

It was clear from the student comments, and supported in the findings, that students experienced each of these four actions regarding their perceptions of the concept of leadership. Through guided critical reflection, students expressed expanded definitions of leadership, new perspectives of leadership characteristics and responsibilities, changes to what they thought leadership entailed, and gained an appreciation for the role of reflection in continued leadership development. Furthermore, students were able to demonstrate autonomous thinking by acknowledging the impact their newly gained skills and knowledge may have on others. By carefully selecting educational activities that require critical reflection, occupational therapy leadership educators may elicit a transformative learning experience for their students.

\section{Practical Implications}

While findings from qualitative research cannot be generalized to other populations, the findings of this study may be transferable such that insight gained may inform other leadership course designs (Merriam, 2009). Student perceptions of their lived experience within an online leadership course may be applicable to other students of similar characteristics. Since post-professional OTD degree programs continue to be developed across the United States, program directors and leadership instructors may find these results helpful.

When designing future online leadership courses for occupational therapists, there are several factors that educators might wish to consider in order to elicit a transformative learning experience. The course designer should consider building assignments that require a scaffolding approach to reflection so that students become proficient with reflection and learn to incorporate it into their ongoing development. It is also important to foster an environment of support and collegiality that allows class discussion to facilitate introspection, narrative processing, and application of the material. Selection of appropriate learning materials is critical to the student experience as well. Students voiced greater appreciation for materials that were relevant and application-based with real world examples of leadership situations. Particularly, students appreciated The 21 Irrefutable Laws of Leadership: Follow Them and People Will Follow You (Maxwell, 2007) and the TED Talk "Everyday Leadership" recorded by Drew Dudley (2010). Helping students view leadership as an occupation will enable them to critically analyze their performance through the lens of an occupational therapy model of practice such as the person-environment-occupation model (Law et al., 1996).

\section{LIMITATIONS AND TRUSTWORTHINESS}

There are a few noteworthy limitations of the present study. Because this study is qualitative, results are not generalizable to other populations (Merriam, 2009). However, transferability was ensured through the use of thick, rich descriptions of participant comments and maximum variation of the sample by including data from students of varying ages, levels of experience, practice settings, and of both genders. 
Most of the data used for this study were collected from forum discussions that were graded assignments within the course. As such, students may have written answers they believed would earn them the highest grades, not necessarily honest answers reflecting their true opinions and beliefs. Similarly, while students were informed about the anonymous nature of the summative end of course evaluations, it is possible that some students either did not complete the evaluations or were not fully honest with their responses out of fear that they were not actually anonymous and negative responses may affect their course grade. To mitigate the effect of these limitations, including student responses from both the discussion forum and the course evaluations used data triangulation. Additionally, the high volume of participant responses collected as data will support the trustworthiness of the results.

The researcher was the professor and developer of the course under study. Therefore, it was imperative that she recognized the potential for bias. Throughout the study, the researcher kept a reflexive journal, which allowed her to bracket her biases and assumptions so that she could analyze the data objectively. However, since the data were in the form of documents that were collected and analyzed after the students were no longer enrolled in the University, the potential for observer bias was eliminated.

Finally, a significant limitation is the fact that the leadership course took place in the final semester of the post-professional OTD curriculum. It became apparent in the data coding process that while the forum instructions asked students to reflect upon their experiences in the course, many students included their entire doctoral study experience in their responses. Because of this, it was difficult to determine definitively that the findings of this study were outcomes of the leadership course rather than outcomes of the entire doctoral experience.

Trustworthiness is dependent upon the rigor involved in study design, data collection, and data analysis (Merriam, 2009). There are several components of trustworthiness that must be addressed: credibility, confirmability, dependability, and transferability (Carpenter \& Suto, 2008). Trustworthiness was ensured throughout this study in a variety of ways, some of which are limited due to the use of existing data. Method triangulation was used as two different document sources were analyzed (course evaluations and forum posts). Data triangulation was utilized because the data were collected from five different cohorts spanning from 2014 through 2016. Peer debriefing was completed by having another educator who was familiar with higher educational pedagogy and occupational therapy leadership review the procedures, data analysis, and findings. The researcher relied upon reflexivity through journaling to bracket her relationship with the students and course, and her preconceived notions of occupational therapy leadership development. An audit trail was kept throughout the research process to document all procedures and decisions. While all students were occupational therapists, there is still maximum variation in the sample since students had a variety of clinical experience, a variety of leadership experience, came from a variety of practice settings and geographical locations, were of both genders, were of a variety of ages, and had a variety of educational backgrounds. 


\section{RECOMMENDATIONS FOR FUTURE RESEARCH}

There are several recommendations for future research that would be advantageous. To increase the trustworthiness of the findings further, it would be beneficial to conduct the same study on a different leadership course delivered at a different university. Since this study focused solely on the perceptions of post-professional doctoral students, a similar study should be conducted to examine the perceptions of entry-level occupational therapy students as the lack of clinical experience and age difference may elicit different experiences with a leadership course. Additionally, since a qualitative study only ascertains participant perceptions, a companion quantitative study would be beneficial. Quantitatively, a researcher could determine if factors such as age, years of clinical experience, years of titled leadership experience, or gender have an effect on the transformative learning process. Furthermore, the effectiveness of different teaching strategies could be evaluated to determine whether a specific method is most likely to result in transformative learning. Lastly, a follow-up study of the same students would be beneficial to determine whether they actually assumed more leadership roles after completion of the course.

\section{References}

American Occupational Therapy Association. (2007). AOTA's Centennial Vision and executive summary. American Journal of Occupational Therapy, 61(6), 613-614. https://doi.org/10.5014/ajot.61.6.613

American Occupational Therapy Association. (2013). AOTA strategic goals \& objectives: 2014 to 2017. Retrieved from http://www.aota.org/AboutAOTA/GetInvolved/BOD/2014-17-Strategic-Goals.aspx

American Occupational Therapy Association. (2017). Vision 2025. American Journal of Occupational Therapy, 71, 7103420010. https://doi.org/10.5014/ajot.2017.713002

Bangert, A. W. (2004). The seven principles of good practice: A framework for evaluating on-line teaching. Internet and Higher Education, 7(3), 217-232. https://doi.org/10.1016/j.iheduc.2004.06.003

Bayer, M. A. (2012). The effectiveness of student leadership development programs at a Midwestern university (Doctoral dissertation). Retrieved from ProQuest Dissertations \& Theses Global. (Order No. 3524436)

Carpenter, C., \& Suto, M. (2008). Qualitative research for occupational and physical therapists: A practical guide. Ames, IA: Blackwell Publishing.

Cole, M. B., \& Tufano, R. (2008). Applied theories in occupational therapy: A practical approach. Thorofare, NJ: SLACK Incorporated.

Creswell, J. W. (2014). Research design: Qualitative, quantitative, and mixed methods approaches $\left(4^{\text {th }}\right.$ ed.). Thousand Oaks, CA: SAGE Publications.

Dinh, J. E., Lord, R. G., Gardner, W. L., Meuser, J. D., Liden, R. C., \& Hu, J. (2014). Leadership theory and research in the new millennium: Current theoretical trends and changing perspectives. The Leadership Quarterly, 25(1), 36-62. https://doi.org/10.1016/j.leaqua.2013.11.005 
Dopson, S., Ferlie, E., McGivern, G., Fischer, M.D., Ledger, J., Behrens, S., \& Wilson, S. (2016). The impact of leadership and leadership development in higher education: A review of the literature and evidence. Retrieved from http://researchbank.acu.edu.au/cgi/viewcontent.cgi?article=1557\&context=flb pub

Dudley, D. (2010, September). Everyday leadership [video file]. Retrieved from https://www.ted.com/talks/drew dudley everyday leadership

Farkas, J. S. (2014). Leadership education: A pilot study investigating employer and student perceptions of value. (Unpublished master's thesis). Wright State University, Ohio.

Fleming-Castaldy, R. P., \& Patro, J. (2012). Leadership in occupational therapy: Selfperceptions of occupational therapy managers. Occupational Therapy in Health Care, 26(2-3), 187-202. https://doi.org/10.3109/07380577.2012.697256

Fletcher, M. A., Zuber-Skerritt, O., Bartlett, B., Albertyn, R., \& Kearney, J. (2010). Metaaction research on a leadership development program: A process model for lifelong learning. Systemic Practice and Action Research, 23(6), 487-507. https://doi.org/10.1007/s11213-010-9173-5

Fitzpatrick, M. R., \& Stalikas, A. (2008). Positive emotions as generators of therapeutic change. Journal of Psychotherapy Integration, 18(2), 137-154. http://psycnet.apa.org/doi/10.1037/1053-0479.18.2.137

Haber-Curran, P., \& Tillapaugh, D. W. (2015). Student-centered transformative learning in leadership education: An examination of the teaching and learning process. Journal of Transformative Education, 13(1), 65-84. https://doi.org/10.1177/1541344614559947

Harvey, M., \& Jenkins, D. M. (2014). Knowledge, praxis, and reflection: The three critical elements of effective leadership studies programs. Journal of Leadership Studies, 7(4), 76-85. https://doi.org/10.1002/jls.21314

Heard, C. (2014). Choosing the path of leadership in occupational therapy. The Open Journal of Occupational Therapy, 2(1), 1-18. https://doi.org/10.15453/2168-6408.1055

Jenkins, D. M. (2012). Exploring signature pedagogies in undergraduate leadership education. Journal of Leadership Education, 11(1), 1-27. https://doi.org/10.12806/V11//1/RF1

Kiersch, C., \& Peters, J. (2017). Leadership from the inside out: Students leadership development within authentic leadership and servant leadership frameworks. Journal of Leadership Education, 16(1), 148- 168. https://doi.org/1012806/V16/l1/T4

Kouzes, J. M., \& Posner, B. Z. (2012). The leadership challenge ( $5^{\text {th }}$ ed.). San Francisco, CA: The Leadership Challenge.

Law, M., Cooper, B., Strong, S., Steward, D., Rigby, P., \& Letts, L. (1996). The personenvironment-occupation model: A transactive approach to occupational therapy. Canadian Journal of Occupational Therapy, 63(1), 9-23. https://doi.org/10.1177/000841749606300103

Leedy, P. D., \& Ormrod, J. E. (2016). Practical research: Planning and design (11 ${ }^{\text {th }}$ ed.). Boston, MA: Pearson. 
Lévesque, M., Hovey, R., \& Bedos, C. (2013). Advancing patient-centered care through transformative educational leadership: A critical review of health care professional preparation for patient-centered care. Journal of Healthcare Leadership, 5, 35-46. https://doi.org/10.2147/JHL.S30889

Maxwell, J. C. (2007). The 21 irrefutable laws of leadership: Follow them and people will follow you (10 $10^{\text {th }}$ ed.). Nashville, TN: Thomas Nelson.

Merriam, S. B. (2009). Qualitative research: A guide to design and implementation. San Francisco, CA: Jossey-Bass.

Mezirow, J. (1997). Transformative learning: Theory to practice. New Directions of Adult and Continuing Education, 1997(4), 5-12. https://doi.org/10.1002/ace.7401

Patient Protection and Affordable Care Act; HHS Notice of Benefit and Payment Parameters for 2012, 78 Fed. Reg. 15410 (March 11, 2013) (to be codified at 45 C.F.R. pts. 153, 155,156, 157, \& 158).

Provident, I. M., Salls, J., Dolhi, C., Schreiber, J., Mattila, A., \& Eckel, E. (2015). Design of an online curriculum promoting transformative learning in post professional doctoral students. Online Learning Journal, 19(3), 128-143. https://doi.org/10.24059/olj.v19i3.672

QSR International. (2015, September 28). Introducing the new NVivo [video file]. Retrieved from https://www.youtube.com/watch?v=RYpRvjFI-pM

Rudestam, K. E., \& Newton, R. R. (2015). Surviving your dissertation $\left(4^{\text {th }}\right.$ ed). Thousand Oaks, CA: SAGE Publications, Ltd.

Ryan, M. (2013). The pedagogical balancing act: Teaching reflection in higher education. Teaching in Higher Education, 18(2), 144-155. https://doi.org/10.1080/13562517.2012.694104

Scott, W. E. (1985). Variables that contribute to leadership among female occupational therapists. American Journal of Occupational Therapy, 39(6), 379-385. https://doi.org/10.5014/ajot.39.6.379

Singleton, M. K. (2012). A design, implementation, and evaluation of Pierce College student leadership development program (Doctoral dissertation). Retrieved from ProQuest Dissertations \& Theses Global. (Order No. 3493826)

Sloan, A., \& Bowe, B. (2014). Phenomenology and hermeneutic phenomenology: the philosophy, the methodologies, and using hermeneutic phenomenology to investigate lecturers' experiences of curriculum design. Quality \& Quantity, 48(3), 1291-1303. https://doi.org/10.1007/s11135-013-9835-3

Smith, K. K. (2005). Exploring alumnae long-term perceptions of an undergraduate leadership course: A case study (Doctoral dissertation). Retrieved from ProQuest Dissertations \& Theses Global. (Order No. 3190011)

Stoffel, V. C. (2013). From heartfelt leadership to compassionate care (Inaugural Presidential Address). American Journal of Occupational Therapy, 67, 633-640. https://doi.org/10.5014/ajot.2013.676001

Taylor, E. W. (2007). An update of transformative learning theory: A critical review of the empirical research (1999-2005). International Journal of Lifelong Education, 26(2), 173-191.https://doi.org/10.1080/02601370701219475

Terrion, J. L., \& Leonard, D. (2007). A taxonomy of the characteristics of student peer mentors in higher education: Findings from a literature review. Mentoring \& Tutoring, 15(2), 149-164. https://doi.org/10.1080/13611260601086311 